\title{
Clinicopathologic and Immunohistochemical Findings from Autopsy of Patient with COVID-19, Japan
}

Takuya Adachi, Ja-Mun Chong, Noriko Nakajima, Masahiro Sano, Jun Yamazaki, Ippei Miyamoto, Haruka Nishioka, Hidetaka Akita, Yuko Sato, Michiyo Kataoka, Harutaka Katano, Minoru Tobiume, Tsuyoshi Sekizuka, Kentaro Itokawa, Makoto Kuroda, Tadaki Suzuki

An autopsy of a patient in Japan with coronavirus disease indicated pneumonia lung pathology, manifested as diffuse alveolar damage. We detected severe acute respiratory syndrome coronavirus 2 antigen in alveolar epithelial cells and macrophages. Coronavirus disease is essentially a lower respiratory tract disease characterized by direct viral injury of alveolar epithelial cells.

Crer oronavirus disease (COVID-19), which was first reported in December 2019 in Wuhan, China, has been spreading rapidly and on a global scale. The causative virus is severe acute respiratory syndrome coronavirus 2 (SARS-CoV-2) (1). The World Health Organization declared the outbreak of COVID-19 to be pandemic on March 11, 2020, and had reported 693,282 laboratory-confirmed cases and 33,106 deaths globally as of March 30 (2). Numerous studies of the clinical features of COVID-19 and the virologic characteristics of SARS-CoV-2 have been conducted in China to date $(3,4)$. Postmortem examination will provide valuable information required to elucidate the pathogenesis of COVID-19; however, only 2 studies have been published on COVID-19 pathology thus far $(5,6)$. Further, the distribution of SARS-CoV-2 in a patient and identification of which cells are infected by SARS-CoV-2 have yet to be reported.

We describe the clinical course and the pathologic and virologic findings upon autopsy of a passenger

Affiliations: Toshima Hospital, Tokyo, Japan (T. Adachi, J.-M.

Chong, M. Sano, J. Yamazaki, I. Miyamoto, H. Nishioka, H. Akita); National Institute of Infectious Diseases, Tokyo, Japan

(N. Nakajima, Y. Sato, M. Kataoka, H. Katano, M. Tobiume,

T. Sekizuka, K. Itokawa, M. Kuroda, T. Suzuki)

DOI: https://doi.org/10.3201/eid2609.201353 on a cruise ship who died from COVID-19. The ship departed the port of Yokohama, Japan, on January 20, 2020 , with a total of 3,711 passengers and crew; 712 $(19 \%)$ of the persons on board were laboratory confirmed as having COVID-19. Of those, 12 had died as of March 31 (7).

\section{Case Report}

The passenger, an 84-year-old woman from Japan who had no notable medical history, had onset of fever $\left(38.8^{\circ} \mathrm{C}\right)$ on February 5, followed by diarrhea (Table 1). On February 9, she went to the ship's medical office with shortness of breath, and a throat swab sample was taken. Three days later (illness day 8), she was admitted to Toshima Hospital (Tokyo, Japan) with dyspnea on exertion; body temperature was $38.2^{\circ} \mathrm{C}$, pulse rate 70 beats $/ \mathrm{min}$, blood pressure $156 / 80 \mathrm{~mm} \mathrm{Hg}$, respiratory rate 16 breaths/min, and oxygen saturation 95\% (with $2 \mathrm{~L} / \mathrm{min}$ oxygen supplementation). A chest radiograph showed opacities in both lungs, and a computed tomography scan revealed ground glass opacities and consolidations, mainly in bilateral lower lung lobes (Figure 1, panels A-C). The diagnosis of COVID-19 was confirmed by real-time reverse transcription PCR on the throat swab and reported on illness day 9. On illness day 10, hypoxia progressed, even with $15 \mathrm{~L} /$ min oxygen supplementation. The patient expressly stated that she did not want mechanical ventilation. Ampicillin/ sulbactam was administered intravenously, based on the identification of Klebsiella pneumoniae and methicillin-sensitive Staphylococcus aureus by sputum culture. Corticosteroids were added after the appearance of progressive hypoxemia and acute respiratory distress syndrome. On illness day 13, the antiretroviral 
Table 1. Symptoms, signs, laboratory results, and treatment administered for an 84-year-old woman who died from coronavirus disease, by day of illness, cruise ship and Toshima Hospital, Tokyo, Japan, February $2020^{*}$

\begin{tabular}{|c|c|c|c|c|c|c|c|c|c|c|c|c|c|c|c|}
\hline \multirow[b]{3}{*}{ Characteristic } & \multicolumn{15}{|c|}{ Day of illness } \\
\hline & \multicolumn{6}{|c|}{ Cruise ship } & \multicolumn{9}{|c|}{ Hospital } \\
\hline & 1 & 3 & 4 & 5 & 6 & 7 & 8 & 9 & 10 & 11 & 12 & 13 & 14 & 15 & 16 \\
\hline \multicolumn{16}{|l|}{ Symptom } \\
\hline Temperature, ${ }^{\circ} \mathrm{C}$ & 38.8 & & & 38.5 & & 38.9 & 38.3 & 37.9 & 37.5 & 37.1 & 37.2 & 37.5 & 37.7 & 36.9 & \\
\hline $\begin{array}{l}\text { Dyspnea† } \\
\mathrm{SaO}_{2}, \%\end{array}$ & & & + & + & + & + & $\begin{array}{c}++ \\
95-96\end{array}$ & $\begin{array}{c}++ \\
90-95\end{array}$ & $\begin{array}{c}++ \\
86-94\end{array}$ & $\begin{array}{c}++ \\
84-92\end{array}$ & $\begin{array}{c}+++ \\
83-86\end{array}$ & $\begin{array}{c}+++ \\
79-84\end{array}$ & $\begin{array}{c}+++ \\
74-84\end{array}$ & $\begin{array}{c}+++ \\
66-79\end{array}$ & +++ \\
\hline \multicolumn{16}{|l|}{ Intervention } \\
\hline $\mathrm{O}_{2}(\mathrm{~L} / \mathrm{min})$ & & & & & & & 2 & 5 & 15 & 15 & 15 & 15 & 15 & 15 & 15 \\
\hline ABPC/SBT & & & & & & & & & & * & * & * & * & * & \\
\hline MPSL, HYD & & & & & & & & & * & * & * & & * & * & * \\
\hline $\mathrm{LPV} / \mathrm{r}$ & & & & & & & & & & & & * & * & * & \\
\hline Morphine & & & & & & & & & & & & & * & * & * \\
\hline \multicolumn{16}{|l|}{ Blood test result } \\
\hline Leukocytes, $10^{3} / \mu \mathrm{L}$ & & & & & & & 3.7 & & 4.2 & & & 12.4 & & & \\
\hline $\mathrm{PLT}, 10^{4} / \mu \mathrm{L}$ & & & & & & & 13.4 & & 14.0 & & & 22.8 & & & \\
\hline AST, U/L & & & & & & & 53 & & 58 & & & 46 & & & \\
\hline $\mathrm{ALT}, \mathrm{U} / \mathrm{L}$ & & & & & & & 25 & & 26 & & & 28 & & & \\
\hline $\mathrm{CRE}, \mathrm{mg} / \mathrm{dL}$ & & & & & & & 0.71 & & 0.64 & & & 0.63 & & & \\
\hline $\mathrm{CRP}, \mathrm{mg} / \mathrm{dL}$ & & & & & & & 2.66 & & 3.40 & & & 1.32 & & & \\
\hline
\end{tabular}

drug lopinavir/ritonavir was added orally. Despite all these treatment efforts, the dyspnea progressed and chest radiograph findings worsened (Figure 1, panel D). Intravenous morphine was initiated to alleviate breathing difficulties from illness on day 14 . The patient died from respiratory failure on February 20 (illness day 16). The patient's family gave consent for an autopsy to be performed.

An autopsy was conducted 5 hours after death, with the exception of the brain and bone marrow. Macroscopically, the trachea and bronchi exhibited neither redness nor erosion; however, the lungs (left, 590 g; right, $690 \mathrm{~g}$ ) were partially dark red, consolidated, and airless. The cut surface was slightly sticky. Specifically, both pleurae were slightly thickened, with pleural effusions of $<1 \mathrm{~mL}$ in each pleural cavity. The heart (420 g) showed right ventricular dilatation, with $10 \mathrm{~mL}$ of cardiac effusion. We noted diffuse multiple punctate hemorrhages in the mucosa of the stomach and duodenum. Histologic analysis revealed that the lungs exhibited features of both exudative and organizing diffuse alveolar damage (DAD). The lung tissues in the exudative phase of DAD showed prominent hyaline membranes (Figure 2, panel A), and those in the organizing phase of DAD showed desquamation, squamous metaplasia of the epithelial cells (Figure 2, panel B), organizing hyaline membranes (Figure 2, panel C), and inflammatory cell infiltration with prominent plasma cells in the alveolar septa (Figure 2, panel D). We observed intra-alveolar hemorrhage, vascular congestion, and hyperplasia of type 2 pneumocytes. We also noted multinucleated syncytial cells. In addition, we detected hemophagocytosis in the lungs, spleen, and lymph nodes (Figure 2, panel E). The glomeruli of both kidneys were marked by microthrombi, suggesting early signs of disseminated intravascular coagulation (Figure 2, panel F). We observed no notable changes in the other organs.
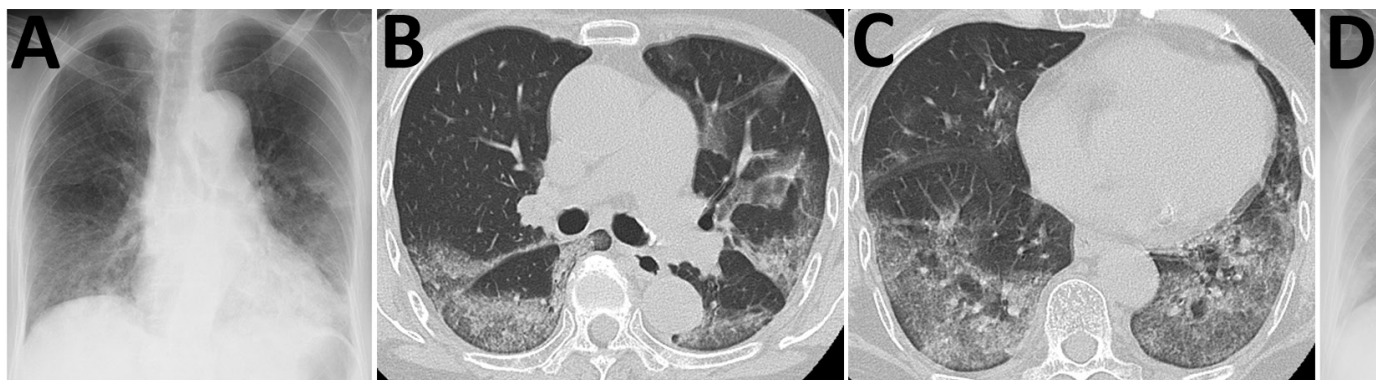

Figure 1. Chest radiograph and computed tomography results from an 84-year-old woman who died from coronavirus disease, Toshima Hospital, Tokyo, Japan, February 2020. A) Chest radiographs taken on admission (illness day 8), showing reticular shadows, mainly in bilateral lower lung fields. B, C) Chest computed tomography scan taken on illness day 8 , indicating ground-glass opacities mainly located in posterior segments of the bilateral lower lobes, where the highest numbers of viral RNA copies were found on autopsy.

D) Chest radiographs taken on illness day 14 , with shadows spreading to almost entire lungs and exhibiting air bronchograms. 
Figure 2. Pathologic findings for the lungs, lymph nodes, and kidneys in an autopsy of an 84-year-old woman who died from coronavirus disease, Toshima Hospital, Tokyo, Japan, February 2020. A) Marked diffuse alveolar damage in exudative phase with prominent hyaline membrane formation in lung tissues. Hematoxylin \& eosin (H\&E) staining. Scale bar indicates $200 \mu \mathrm{m}$. B, C) Desquamation and squamous metaplasia of the epithelium (B) and organized hyaline membranes $(C)$, with septal fibrosis in the organizing phase lesions in lung sections. H\&E staining. Scale bar indicates $200 \mu \mathrm{m}$. D) Inflammatory infiltrate comprised

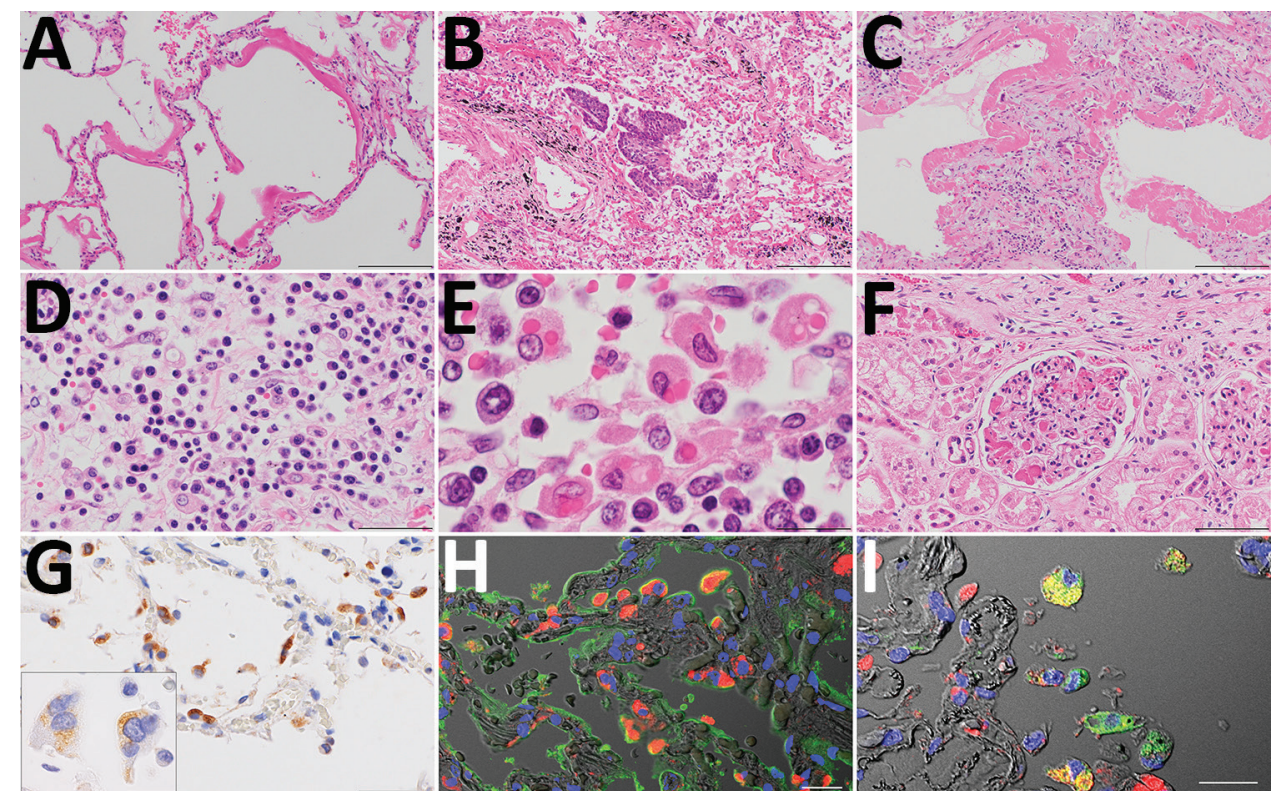
predominately of plasma cells in the alveolar septa. H\&E staining. Scale bar indicates $50 \mu \mathrm{m}$. E) Obvious erythrophagocytic macrophages in the lymph nodes. H\&E staining. Scale bar indicates $20 \mu \mathrm{m}$. F) Numerous microthrombi in the glomerulus in the kidneys. H\&E staining. Scale bar indicates $100 \mu \mathrm{m} . \mathrm{G}$ ) Immunostaining (brown) of severe acute respiratory syndrome coronavirus 2 antigen in alveolar epithelial cells. Scale bar indicates $50 \mu \mathrm{m}$. Inset: multinucleated syncytial cells; scale bar indicates $20 \mu \mathrm{m}$. $\mathrm{H}$, I) Double immunofluorescence staining for severe acute respiratory syndrome coronavirus 2 (red) with epithelial cell marker $(\mathrm{H}$; epithelial membrane antigen staining, green); macrophage marker (I; anti-CD68 antibody staining, green) in the same cell. TO-PRO-3 nucleic acid staining (blue) and differential contrast images are also shown. Scale bar indicates $20 \mu \mathrm{m}$.

To examine the distribution of SARS-CoV-2 antigens, we performed immunohistochemistry on all tissue sections by using rabbit polyclonal antibodies against the SARS-CoV nucleocapsid protein (8). We confirmed the reactivity of the antibody by using SARS-CoV-2-infected VeroE6/TMPRSS2 cells as a positive control and a mock-infected VeroE6/ TMPRSS2 cells as a negative control (9). We detected SARS-CoV-2 antigens in the cytoplasm of alveolar epithelial cells in earlier-stage DAD lesions, with mild inflammation before formation of hyaline membranes (Figure 2, panel G) rather than progressed lesions. We also detected viral antigens detected in the cytoplasm of multinucleated syncytial cells (Figure 2, panel G, inset). We detected no signals in the trachea, intestine, or other extrapulmonary tissue sections. Double immunofluorescence staining revealed that the viral antigen was present in epithelial membrane antigen-positive alveolar epithelial cells and CD68 (clone PGM-1)-positive alveolar macrophages (Figure 2, panels $\mathrm{H}$ and I).

We determined copy numbers of SARS-CoV-2RNA in various specimens by using real-time reverse transcription PCR to amplify a segment in the nucleocapsid protein-encoding region of SARS-CoV-2 RNA, using forward (5\$-GGCCGCAAATTGCACAAT-3\$) and reverse (5\$-CCAATGCGCGACATTCC-3\$) primers, and a labeled probe $5 \$$-(FAM)-CCCCCAGCGCTTCAGC-
GTTCT-(TAMRA)-3\$ (Table 2). We collected postmortem tissues by using a new set of forceps and scissors for each sample to avoid cross-contamination. We used the amount of human glyceraldehyde-3-phosphate dehydrogenase mRNA in the RNA extracted from each tissue as an internal reference for normalization. Although SARS-CoV-2 RNA loads in serum samples increased from illness day 8 to day 13, at the time of autopsy, we detected SARS-CoV-2 RNA at low levels in whole blood and feces but not in urine. The copy numbers of SARS-CoV-2 RNA detected in the swab samples collected during the autopsy were higher in the right bronchus than in the nasopharynx. In addition, SARS-CoV-2 RNA glyceraldehyde-3-phosphate dehydrogenase mRNA ratios in each tissue sample showed that viral loads in peripheral lung tissues were higher than those in trachea, bronchi, and upper respiratory tract tissues. We also detected low levels of SARSCoV-2 RNA in nonrespiratory tract tissues, including the colon, liver, and spleen. Whole-genome sequencing of SARS-CoV-2 from the lung of the patient did not indicate substantial mutations except for a few singlenucleotide variations, including G11083T transversion compared with Wuhan-Hu-1 (GenBank accession no. MN908947; GISAID identification no. EPIISL402125), which is shared by the isolates obtained from the Diamond Princess cruise ship outbreak. 
Table 2. Quantification of SARS-CoV-2 RNA in multiple specimens from an 84-year-old woman who died from coronavirus disease, Toshima Hospital, Tokyo, Japan, February 2020*

\begin{tabular}{|c|c|c|c|c|c|}
\hline Day of illness & Specimen type or site & SARS-CoV-2 RNA & $\begin{array}{l}\text { SARS-CoV-2, } \\
\text { copies/reaction }\end{array}$ & $\begin{array}{c}\text { GAPDH, } \\
\text { copies/reaction }\end{array}$ & $\begin{array}{l}\text { SARS-CoV-2 to } \\
\text { GAPDH, ratio }\end{array}$ \\
\hline Day 8 (admission) & Serum, copies $/ \mu \mathrm{L}$ & $2.7 \times 10^{1}$ & & & \\
\hline Day 10 & & $6.2 \times 10^{1}$ & & & \\
\hline Day 13 & & $2.8 \times 10^{2}$ & & & \\
\hline \multirow[t]{36}{*}{ Day 16 (autopsy) } & $\begin{array}{l}\text { Whole blood, } \\
\text { copies } / \mu \mathrm{L}\end{array}$ & $1.6 \times 10^{2}$ & & & \\
\hline & Urine, copies $/ \mu \mathrm{L}$ & UDL & & & \\
\hline & Feces, copies/ $\mu \mathrm{L}$ & $1.2 \times 10^{2}$ & & & \\
\hline & $\begin{array}{l}\text { Swabs, copies in } 1 \\
\mu \mathrm{L} \text { medium }\end{array}$ & & & & \\
\hline & Nasopharynx & $2.9 \times 10^{3}$ & & & \\
\hline & Trachea & $1.5 \times 10^{2}$ & & & \\
\hline & Right bronchus & $6.6 \times 10^{4}$ & & & \\
\hline & Left bronchus & $1.3 \times 10^{2}$ & & & \\
\hline & Rectum & $3.7 \times 10^{1}$ & & & \\
\hline & Frozen tissues & & & & \\
\hline & Pharynx & & 83 & 2,670 & $3.1 \times 10^{-2}$ \\
\hline & Tonsils & & UDL & 3,730 & NA \\
\hline & Epiglottis & & 43 & 13,000 & $3.3 \times 10^{-3}$ \\
\hline & Trachea & & UDL & 145 & NA \\
\hline & Right bronchus & & 840 & 421 & $2.0 \times 10^{0}$ \\
\hline & Right lung & & & & \\
\hline & Upper, S1/S2 & & 76,600 & 1,570 & $4.9 \times 10^{1}$ \\
\hline & Upper, S3 & & 584 & 82 & $7.1 \times 10^{0}$ \\
\hline & Middle, S5 & & 11,900 & 3,000 & $4.0 \times 10^{0}$ \\
\hline & Lower, S6 & & 37,100 & 1,230 & $3.0 \times 10^{1}$ \\
\hline & Lower, S8/S9 & & 21,500 & 1,860 & $1.2 \times 10^{1}$ \\
\hline & Lower, S7/S10 & & 17,100 & 221 & $7.7 \times 10^{1}$ \\
\hline & Left bronchus & & 67 & 93 & $7.2 \times 10^{-1}$ \\
\hline & Left lung & & & & \\
\hline & Upper, S1+2 & & 56,500 & 2,300 & $2.5 \times 10^{1}$ \\
\hline & Upper, S3 & & 26,300 & 12,600 & $2.1 \times 10^{0}$ \\
\hline & Upper, S4/S5 & & 6,260 & 1,530 & $4.1 \times 10^{0}$ \\
\hline & Lower, S6 & & 80,500 & 1,840 & $4.4 \times 10^{1}$ \\
\hline & Lower, S8/S9 & & 1,000 & 325 & $3.1 \times 10^{0}$ \\
\hline & Lower, S10 & & 22,900 & 977 & $2.3 \times 10^{1}$ \\
\hline & Heart & & UDL & 64,800 & NA \\
\hline & Liver & & 57 & 104,000 & $5.5 \times 10^{-4}$ \\
\hline & Kidney & & UDL & 5,910 & NA \\
\hline & Spleen & & 259 & 444,000 & $6.0 \times 10^{-4}$ \\
\hline & Pancreas & & UDL & 3,690 & NA \\
\hline & Colon & & 35 & 5,030 & $7.0 \times 10^{-3}$ \\
\hline
\end{tabular}

*GAPDH, glyceraldehyde-3-phosphate dehydrogenase; NA, not applicable; S, segment; SARS-CoV-2; severe acute respiratory syndrome coronavirus 2; UDL, under detection limit (<10 copies/reaction).

\section{Conclusions}

We report an autopsy of an 84-year-old cruise ship passenger who died from COVID-19. Lung pathology showed exudative and organizing phases of DAD, similar to what is observed in cases of severe acute respiratory syndrome (10-13). We detected SARSCoV-2 antigen in alveolar epithelial cells and alveolar macrophages, also similar to what is observed in cases of severe acute respiratory syndrome $(14,15)$. COVID-19 begins with upper respiratory tract symptoms (3) and ultimately becomes a lower respiratory tract disease in the later stages, based on the higher copy numbers of SARS-CoV-2 in the lower respiratory tract, relative to serum, whole blood, urine, feces, and rectal swab specimens taken during the clinical course and after death. COVID-19 is probably caused by direct injury of alveolar epithelial cells by SARS$\mathrm{CoV}-2$, accompanied by secondary damage to nonrespiratory organs. The high prevalence of SARS-CoV-2 infection on the cruise ship could not be attributed to specific genetic mutations of the virus.

\section{Acknowledgments}

Our deepest condolences go to the family of the patient, who was a caring mother and grandmother, and for whom a cruise ship vacation was a lifetime dream. We thank the patient's family, who generously offered us an opportunity to explore the pathology of this unknown disease, despite their grief at the loss of their family member. We also thank our nursing team at Toshima 
Hospital for their diligent patient care; our pathology technicians, Asako Kusunoki, Yoko Shibasaki, and Misaki Hisawa, for their contributions to the autopsy; and Tsunekazu Hishima, Toru Motoi, and Masafumi Takimoto for their advice on pathologic diagnosis.

This study was supported in part by grants-in-aid from the Japan Agency for Medical Research and Development (AMED) to M.K. (grant nos. JP19fk0108104 and JP19fk0108103), T.S. (grant nos. JP19fk0108104, JP19fk0108110, and JP19fk0108082), and N.N. (grant no. JP19fk0108082).

\section{About the Author}

Dr. Adachi is the chief of the Department of Infectious Diseases at Toshima Hospital. His primary research interests include clinical management in an outbreak. He has been part of international outbreak response teams for Ebola disease, yellow fever, diphtheria, and cholera.

\section{References}

1. World Health Organization. Naming the coronavirus disease (COVID-19) and the virus that causes it [cited 2020 Mar 28]. https://www.who.int/emergencies/diseases/novelcoronavirus-2019/technical-guidance/naming-thecoronavirus-disease-(covid-2019)-and-the-virus-that-causes-it

2. World Health Organization. Coronavirus disease 2019 (COVID-19) situation report 67 [cited 2020 Mar 30]. https:/ /www.who.int/emergencies/diseases/novelcoronavirus-2019/situation-reports

3. Chen N, Zhou M, Dong X, Qu J, Gong F, Han Y, et al. Epidemiological and clinical characteristics of 99 cases of 2019 novel coronavirus pneumonia in Wuhan, China: a descriptive study. Lancet. 2020;395:507-13. https:/ / doi.org/ 10.1016/S0140-6736(20)30211-7

4. Lu R, Zhao X, Li J, Niu P, Yang B, Wu H, et al. Genomic characterisation and epidemiology of 2019 novel coronavirus: implications for virus origins and receptor binding. Lancet. 2020;395:565-74. https:// doi.org/10.1016/ S0140-6736(20)30251-8

5. Xu Z, Shi L, Wang Y, Zhang J, Huang L, Zhang C, et al. Pathological findings of COVID-19 associated with acute respiratory distress syndrome. Lancet Respir Med. 2020; 8:420-2. https://doi.org/10.1016/S2213-2600(20)30076-X

6. Tian S, Hu W, Niu L, Liu H, Xu H, Xiao S-Y. Pulmonary pathology of early-phase 2019 novel coronavirus (COVID-19) pneumonia in two patients with lung cancer. J Thorac Oncol. 2020;15:700-4. https://doi.org/10.1016/j.jtho.2020.02.010

7. Japan Ministry of Health, Labor, and Welfare. Press release: current situation of the novel coronavirus infection, as of March 31 [in Japanese] [cited 2020 Mar 31]. https:/ / www. mhlw.go.jp/stf/newpage_10636.html

8. Fukushi S, Mizutani T, Saijo M, Matsuyama S, Miyajima N, Taguchi F, et al. Vesicular stomatitis virus pseudotyped with severe acute respiratory syndrome coronavirus spike protein. J Gen Virol. 2005;86:2269-74. https://doi.org/ 10.1099/vir.0.80955-0

9. Matsuyama S, Nao N, Shirato K, Kawase M, Saito S, Takayama I, et al. Enhanced isolation of SARS-CoV-2 by TMPRSS2-expressing cells. Proc Natl Acad Sci U S A. 2020;117:7001-3. https://doi.org/10.1073/pnas.2002589117

10. Ding Y, Wang H, Shen H, Li Z, Geng J, Han H, et al. The clinical pathology of severe acute respiratory syndrome (SARS): a report from China. J Pathol. 2003;200:282-9. https://doi.org/10.1002/path.1440

11. Franks TJ, Chong PY, Chui P, Galvin JR, Lourens RM, Reid AH, et al. Lung pathology of severe acute respiratory syndrome (SARS): a study of 8 autopsy cases from Singapore. Hum Pathol. 2003;34:743-8. https:/ / doi.org/ 10.1016/S0046-8177(03)00367-8

12. Hwang DM, Chamberlain DW, Poutanen SM, Low DE, Asa SL, Butany J. Pulmonary pathology of severe acute respiratory syndrome in Toronto. Mod Pathol. 2005;18:1-10. https:/ / doi.org/10.1038/modpathol.3800247

13. Gu J, Korteweg C. Pathology and pathogenesis of severe acute respiratory syndrome. Am J Pathol. 2007;170:1136-47. https:// doi.org/10.2353/ajpath.2007.061088

14. Nakajima N, Asahi-Ozaki Y, Nagata N, Sato Y, Dizon F, Paladin FJ, et al. SARS coronavirus-infected cells in lung detected by new in situ hybridization technique. Jpn J Infect Dis. 2003;56:139-41.

15. Nicholls JM, Butany J, Poon LLM, Chan KH, Beh SL, Poutanen S, et al. Time course and cellular localization of SARS-CoV nucleoprotein and RNA in lungs from fatal cases of SARS. PLoS Med. 2006;3:e27. https:// doi.org/10.1371/ journal.pmed.0030027

Address for correspondence: Tadaki Suzuki, Department of Pathology, National Institute of Infectious Diseases, 1-23-1, Toyama, Shinjuku-ku, Tokyo 162-8640, Japan; e-mail: tksuzuki@nih.go.jp 